\title{
Do Child Abuse and Maltreatment Increase Risk of Schizophrenia?
}

\author{
Lucia Sideli ${ }^{1,2}$, Alice Mule ${ }^{1,2}$, Daniele La Barbera ${ }^{2}$ and Robin M. Murray ${ }^{1 凶}$ \\ ${ }^{1}$ Institute of Psychiatry, King's College London, London, UK \\ ${ }^{2}$ Department of Experimental Biomedicine and Clinical Neuroscience, University of Palermo, Palermo, Italy
}

\begin{abstract}
Introduction Although childhood abuse is a recognised risk factor for depression, post-traumatic stress disorder, and substance misuse, its role in the aetiology of psychotic disorder remained controversial. This is in part because the putative effect of childhood trauma on psychosis has been mostly evaluated by small, cross sectional, uncontrolled studies that raised methodological issues.

Methods Papers concerning the association between childhood trauma and psychotic disorders (to November, 2011) were identified using a comprehensive search of PubMed, Psychinfo, and Scopus and analysing reference list of relevant papers. A narrative synthesis was used to summarise results.

Results An association between childhood abuse and psychotic symptoms was consistently reported by large cross sectional surveys with an effect ranging from 1.7 to 15 . However, we cannot conclude that the relationship is causal as lack of longitudinal studies prevent us from fully excluding alternative explanations such as reverse causality. Gender, cannabis use, and depressive and post-traumatic stress disorder symptoms appear to moderate the effect of childhood trauma on psychotic disorders. However, specificity of childhood abuse in psychotic disorders and, particularly, in schizophrenia has not been demonstrated.

Conclusion Although the association between childhood abuse and psychosis has been replicated, the etiological role of such early adversity has yet to be fully clarified. So far none of the studies reported support the hypothesis that childhood abuse is either sufficient or necessary to develop a psychotic disorder. It seems likely that any effect of childhood abuse on schizophrenia needs to be understood in terms of genetic susceptibility and interaction with other environmental risk factors.

Psychiatry Investig 2012;9:87-99
\end{abstract}

Key Words Schizophrenia, Child abuse, Maltreatment, Etiology, Review.

\section{INTRODUCTION}

Following a quarter of a century in which great emphasis was placed on the biological aetiology of schizophrenia, the last decade has been characterised by increasing interest in the social determinants of the illness. This has in part been provoked by evidence of the different incidence of the disorder across regions and ethnicities, and of its association with social adversities in childhood and early adult life., Although studies in the 1960s and 1970s on abnormal communication styles in families of people affected by schizophrenia were flawed, three decades later developmental psychopathology suggests that biological vulnerabilities and early relational experiences have a

Received: January 3, 2012 Revised: January 18, 2012

Accepted: January 18, 2012 Available online: April 30, 2012

$\triangle$ Correspondence: Robin M. Murray, FRS

Box 52, Department of Psychosis Studies, Institute of Psychiatry, KCL, De Crespigny Park, London SE5 8AF, UK

Tel: +44 2078480100, Fax: +44 2078480287, E-mail: robin.murray@kcl.ac.uk

(a) This is an Open Access article distributed under the terms of the Creative Commons Attribution Non-Commercial License (http://creativecommons.org/licenses/by$\mathrm{nc} / 3.0$ ) which permits unrestricted non-commercial use, distribution, and reproduction in any medium, provided the original work is properly cited. joint role in influencing the onset and outcome of mental disorders. ${ }^{3}$ Indeed, advances in genetic research have shown that the small effect reported for the most replicated susceptibility genes for schizophrenia can be understood only postulating an interaction between genes underpinning different biological systems on the one hand, and environmental exposures, such as migration, urbanicity, stimulants and cannabis use ${ }^{4}$ on the other. However there remains controversy over whether childhood abuse can be regarded as one of the crucial environmental exposures. ${ }^{5}$

\section{PREVALENCE OF CHILDHOOD ABUSE IN THE GENERAL POPULATION AND ITS ASSOCIATION WITH PSYCHIATRIC DISORDERS}

According to the Centre for Disease and Prevention, childhood abuse or maltreatment includes any act of commission or omission by a parent or another caregiver that results in harm, potential of harm or threat of harm to a child. ${ }^{6}$ The prevalence of childhood abuse in the general population is difficult to es- 
timate due to inconsistencies between official statistics and surveys based on self-report measures. However, a systematic review reports that in the UK, USA and New Zealand, 5-35\% of children are physically abused by 18 years, $15-30 \%$ of girls and $5-15 \%$ of boys are sexually abused, and up to $10 \%$ psychologically abused and neglected; over $80 \%$ of physical abuse is perpetrated by parents or by parental figure, while sexual abuse is mostly enacted by other relatives or acquaintances. ${ }^{7}$ Maltreatment is often a chronic condition rather than a single experience: according to Gilbert and colleagues ${ }^{7}$ who concluded that repeated abuse over time occurs in $25 \%$ of cases referred to child protection agencies and at least $40 \%$ of such children have been exposed to multiple types of abuse. Neglect has the highest rate of recurrence and association with other types of abuse, followed by physical and sexual abuse.

Consistent evidence from prospective studies ${ }^{8}$ and cross-sectional surveys ${ }^{9,10}$ has shown that early traumas are related to a number of psychiatric outcomes including depression, posttraumatic stress disorder (PTSD), suicide, and alcohol and substance related disorders. The association between adverse childhood experiences and depressive disorders has been widely replicated in retrospective and prospective studies with small to moderate effect size. ${ }^{11,12}$ In most of the prospective studies, risk for depression in abused children is still significant after adjustment for other risk factors at individual and family level (e.g. child temperament, parental socio-economic status, family relationship problems), ${ }^{8}$ and the literature suggests that risk for depression increases with the severity of abuse in a dose-response fashion. ${ }^{12,13}$ Although the majority of studies focused on sexual abuse, ${ }^{12,14}$ a specific effect of this type of abuse has not been proven as only a few studies controlled for other concurrent types of abuse. By contrast, in some recent studies, the association with emotional abuse remained significant after controlling for physical and sexual abuse, suggesting that the psychological component of abuse might itself play a role in the risk for depression. ${ }^{11}$

Childhood abuse affects the risk for child and youth PTSD ${ }^{15}$ and moderates the risk for adult PTSD in individuals exposed to traumatic experience in adulthood. ${ }^{16}$ According to Kearney and colleagues, ${ }^{15} 21-50 \%$ of victims of sexual abuse and up to $50 \%$ of victims of physical abuse develop PTSD by 18 years of age. Meta-analyses suggest that the effect size of sexual abuse ranges from small to moderate. ${ }^{12,14}$ Longitudinal studies have shown that the effect is not entirely confounded by socio-economic status, family stress, and child temperament. ${ }^{8}$

Adolescents ${ }^{17,18}$ and adults ${ }^{19}$ who experienced child abuse are more likely to report suicidal ideation and behaviour. Some reports from population based surveys claim that child abuse accounts up to $50 \%$ of female and $33 \%$ of male suicidal attempts, and that it is not entirely mediated by life time psychiatric co- morbidities, such as PTSD. ${ }^{20,21}$ Evidence from prospective and retrospective studies ${ }^{22,23}$ suggests that severity of abuse and multiple abuse further strengthen the association.

Substance related problems are twice as common among victims of such early adversities compared to the general population. The association has been more consistently replicated for alcohol abuse and dependence $e^{24,25}$ than for illicit drugs ${ }^{26,27}$ and more often for sexual ${ }^{24}$ than for physical abuse. ${ }^{28}$ Moreover, trauma-related risk for alcohol abuse is specific for women, as little or no effect has been described in men. ${ }^{26-28}$ As reported by several cross sectional studies on psychiatric services, clinical practices, and the community, abused women have an average rate of alcohol problems double that of their non-abused counterparts. ${ }^{24}$ Although alcohol misuse increases risk for victimisation in girls, raising issues about reverse causality, a temporal relationship has been consistently found in cohort studies. ${ }^{29,30}$

\section{RECENT REVIEWS ON CHILDHOOD ABUSE AND PSYCHOSIS}

Three recent reviews analysed the association between childhood abuse and psychosis. ${ }^{31-33}$ Read and colleagues ${ }^{31}$ collected 51 studies about childhood abuse and psychosis carried out up till 2004 including a number of samples with psychotic disorders, a few samples of schizophrenic patients, and mixed clinical samples including also non-psychotic disorders. The weighted average prevalence of either sexual or physical abuse was claimed to be $59 \%$ in males and $69 \%$ in females, and the prevalence of both types $19 \%$ in males and $36 \%$ in females. However, the figures and conclusions of this study have been disputed. The same literature was subsequently analysed by Morgan and Fisher, ${ }^{32}$ who excluded those studies based on child and adolescent samples or which consisted to some extent of non-psychotic disorders $(n=20)$. Their results showed a reduction of the previous estimates: the prevalence of either one or other type of abuse was $50 \%$ in both genders and the prevalence of both types was $18 \%$ in males and $26 \%$ in females. In line with what is known about the general population, girls were more exposed to sexual abuse ( $42 \%$ vs. $28 \%$ ), while the prevalence of physical abuse was almost the same in the two genders ( $35 \%$ women vs. $35 \%$ men). A further review by Bendall and colleagues ${ }^{33}$ pointed out the lack of evidence for a stronger effect of childhood trauma on schizophrenic psychosis than on affective psychosis. According to this review, preliminary studies on small adolescent samples did not support specific association with schizophrenia but reported higher prevalence of early adversities in subjects with atypical psychosis, including dissociative symptoms and context-specific hallucinations and delusions, rather than schizophrenic and bipolar disorders. 
Previous reviews also extensively discussed methodological problems that limited the possibility of drawing univocal conclusions about the association between childhood trauma and psychosis. ${ }^{32,33}$ A major criticism is that the use of a retrospective study design prevents any conclusion about the direction of effect and does not exclude alternative explanations. Among these, developmental abnormalities ${ }^{34}$ deserve particular attention, being not only a well recognised risk factor for schizophrenic disorders but also a possible provocation for abuse and maltreatment. Furthermore, most of the research employed a correlational uncontrolled study design with small and diagnostically heterogeneous samples. When a control group was present, some of the results might have been biased by the use of different trauma measures on cases and controls. Despite research supporting the reliability of patients' memories, ${ }^{35,36}$ retrospective assessment cannot exclude recall bias. Finally, the use of different definitions and different instruments to evaluate the presence and severity of abuse considerably limits comparisons across studies. ${ }^{32,33}$

The above represents a synthesis of three reviews just quoted and the major evidence concerning the association between childhood trauma and psychotic disorders. However, we will now proceed to describe different types of studies in detail as well as considering studies too recent to be in the above reviews, and also discuss the issues of specificity and putative moderating variables.

\section{CROSS SECTIONAL SURVEYS}

In the National Comorbidity Survey carried out in the US (NCS), ${ }^{37}$ Shevlin and colleagues evaluated the association between childhood abuse and neglect in non-affective psychosis. All five trauma variables showed an effect size ranging from 1.50 to 2.68 , but physical abuse was the only one statistically significant, even after controlling for depression (Adj OR 3.45). The odds of being psychotic was 3 times greater if a child experienced two traumas, 7 times greater if he/she experienced three to four traumas, and 30 times greater if he/she experienced five traumas, suggesting a dose-response relationship..$^{38}$

The Netherlands Mental Health Survey and Incidence Study (NEMESIS) ${ }^{39}$ assessed the risk of psychotic symptoms in subjects exposed to different type of abuse and emotional neglect which occurred more than once, before 16 years old. At the 3 -year follow up of an unselected sample of the general adult population, the rate of onset psychotic symptoms in victims of childhood trauma was 3 to 14 times higher than in the unexposed group, depending on the severity of symptoms and need for treatment. Adjusting for demographic variables, psychiatric family history, and co-morbidity, any childhood abuse showed strong association with severe psychotic symptoms
(Adj OR 9.3), particularly with delusions (Adj OR 2.8). A doseresponse effect was also found: with increasing number and frequency of abuse, the odds of being psychotic rose up to 48 times in the severe psychopathology group and up to 30 in the need for care group. Of course, once again the childhood abuse was reported retrospectively by the subjects, raising the question of reverse causality.

Using a similar methodology, the Early Developmental Stages of Psychopathology (EDSP) ${ }^{40}$ reported that German adolescents exposed to any life-time traumatic events doubled the risk of presenting three or more psychotic symptoms at three-year follow-up (OR 1.89), though the association was weaker for traumas before age 13 (Adj OR 2.19, 95\%CI 1-4.81). By contrast, no association was found with manic and depressive symptoms. Natural catastrophes, witnessing of terrible events which occurred to others, and physical threat showed a stronger and specific association with psychosis, whereas sexual abuse, rape, and serious accidents were not significantly related. Consistently with previous results, the risk of developing psychotic symptoms increased with the number of traumatic events and also with the experience of intense fear and hopelessness.

A Californian cross-sectional survey on the impact of various types of maltreatments and family dysfunctions ${ }^{41}$ (Adverse Childhood Experiences study, ACE) investigated the prevalence of a specific psychotic symptom, hallucinations. Both physical and sexual abuse were associated with hallucinations (Adj OR 1.7). However, the effect of a single adversity was considerably reduced when controlled for substance abuse, suggesting that substance misuse might moderate the risk for hallucinations in victims of abuse.

More recently, in England, the Adult Psychiatric Morbidity Survey (APMS ${ }^{42}$ found that the odds of reporting any psychotic symptom or of a diagnosis of psychotic disorder was three times higher in those reporting they had been exposed to any sexual abuse before age 16 (Adj OR 3.17) and twelve times higher in those reporting experience of rape (Adj OR 12.05). When sexual abuse in adulthood was entered in the model, the risk for psychosis associated with childhood abuse further increased, suggesting a magnification effect of recent traumatic experiences on the earliest. This moderating effect was more significant on less severe form of childhood abuse (i.e. without intercourse).

Finally, an Australian cohort study concerning psychotic symptoms in those who as children were exposed to bushfires, went on to investigate the effect of other adverse childhood experiences that were retrospectively collected at the 20 year follow up. ${ }^{43}$ Exposure to natural disaster was not related to subclinical psychiatric symptoms, but the latter were strongly associated with physical (OR 5.48) and sexual abuse (OR 2.81). No dose-response effect was found between number of child- 
hood abuse events and psychotic symptoms.

\section{COHORT STUDIES}

Spataro and colleagues ${ }^{44}$ followed up a large cohort of Australians who had been examined by the local forensic medicine unit at a mean age of 9 years because of abuse and compared them with a general population sample. At the nine-year follow up, subjects who experienced penetrative abuse before age 16 were more likely to be recorded in the national psychiatric register as affected by personality disorders (RR 4.7), anxiety and acute stress disorders (RR 3.2), and major affective disorders (RR 2.1) but not by schizophrenia. One criticism of the study concerns the younger age of exposed subjects at the time of data matching (in their 20s vs. 40 s of unexposed); this that might have prevented the researchers from detecting any significant risk for schizophrenia, since its peak occurrence is an age many of the abused individuals had not reached. Alternatively, others have suggested that the protective effect of social intervention might have altered the natural course of the disorders. ${ }^{31,32}$

The study was then repeated ${ }^{45}$ extending the follow-up period up to 40 years and differentiating the childhood sexual abuse into penetrating and non-penetrating. Childhood sexual abuse was strongly associated to PTSD (OR 5.56), alcohol (OR 5.88) and substance abuse (OR 5.96), and cluster B personality disorders (OR 5.51). This time the effect on psychotic disorders was significant (OR 2.13) and similar to that on affective disorders (OR 2.07). Children who were exposed to penetrative sexual abuse were more likely to develop alcohol abuse (OR 2.02) and psychotic disorders (OR 1.98) in adult life.

Arsenault and colleagues evaluated the effect of abuse on minor psychotic symptoms in a birth cohort of British twins. ${ }^{46}$ The risk of reporting at least one psychotic symptom at 12 years old was three times higher among those exposed to maltreatment by an adult (i.e. physical abuse) and four times higher among victims of bullying by peers; no effect was found for trauma without intention to harm, such as a car crash. Controlling for socio-economic status, childrens' psychopathology and genetic liability, multiple traumas were associated with higher risk for psychosis (Adj RR 3.81-4.57) than a single trauma (Adj RR 2.60-3.08).

\section{STUDIES ON HIGH RISK POPULATIONS}

The relationship between early traumas and psychotic symptoms in those at "genetic high risk" for psychosis was investigated by Schürhoff and colleagues ${ }^{47}$ who found that the positive dimension of schizotypy significantly correlated with the childhood trauma score in first degree relatives of schizophrenic pa- tients ( $\mathrm{r} 0.43, \mathrm{p}<0.001$ ), but not of bipolar probands; this suggests that early adversities interact with genetic susceptibility to schizophrenia but not with susceptibility to bipolar disorder, increasing the risk for the former disorder but not the latter.

In a preliminary study ${ }^{48}$ on clinical ultra high risk subjects $(\mathrm{n}=30)$, physical and sexual abuse were related with positive symptoms (respectively rho $0.43, \mathrm{p}<0.05$, and rho 0.42 , $\mathrm{p}<$ 0.05 ), particularly suspiciousness and grandiosity, while physical abuse was associated with anxiety (rho $0.61, \mathrm{p}<0.05)$. A potential limitation of this paper is that the correlation was not controlled for ethnicity which was also associated to psychopathology. In a sample of Dutch adolescents, Lataster and colleagues ${ }^{49}$ showed that being a victim of bullying and being exposed to unwanted sexual experiences increased the likelihood of reporting delusional ideation and hallucinations three to four times. Bullying experiences were also investigated by the Challenging Times study, ${ }^{50}$ in which prodromal symptoms of psychosis were associated with being a bully (OR 9.90) rather than being bullied, physical abuse (OR 5.96), and witnessing domestic violence (OR 4.16). Sexual abuse was not statistically significantly related, possibly because of its low frequency. Furthermore, in a prospective study on clinically ultra high risk young adults, ${ }^{51}$ retrospectively investigated sexual abuse increased the risk of converting prodromal symptoms to first psychosis by almost three times (OR 2.9); due to the low prevalence of sexual molestation and rape in males (3/32), the finding was limited to women (Table 1).

\section{SPECIFICITY OF CHILDHOOD TRAUMA TO SCHIZOPHRENIA: COMPARISON WITH OTHER CLINICAL POPULATIONS}

Although it is clear from the introduction that childhood trauma is a risk factor for a range of psychiatric diseases, only a few studies provided direct comparisons between schizophrenia and other clinical samples, thus allowing an evaluation of the extent to which childhood abuse is a specific risk factor for schizophrenia. As previously seen, results from cohort studies have generally shown that incidence of schizophrenia in abused children is comparable to or lower ${ }^{44}$ than that of affective disorders ${ }^{45}$ though a single survey reported a doubled risk of schizophrenia but no effect in bipolar disorder and depression. ${ }^{40}$ Two recent case control studies investigated prevalence of childhood trauma in severe mental disorders. In a Italian inpatient sample ${ }^{52}$ any type of childhood abuse was associated with 3 times the odds of major depressive disorder $(n=174)$ but 6 times the odds of schizophrenia $(n=305)$. In a subsample of the UK-based Aetiology and Ethnicity of Schizophrenia and Other Psychoses (AESOP) study, ${ }^{53}$ subjects affected by psychotic depression were found to have a lower prevalence of 
childhood adversities (46\%), compared to that observed in patients with schizophrenia (76\%) and bipolar disorder (69\%). However, the definition of trauma employed in this analysis was broad, including parental separation and loss, in addition to abuse. Similar rates of childhood abuse in bipolar and schizophrenic samples were also reported by two other cross sectional studies: ${ }^{54,55}$ in both of these early adversities were associated with earlier onset, greater number of suicide attempts, and substance misuse. By contrast, in a sample of outpatients who spontaneously reported having been abused, Wexler ${ }^{56}$ found that the prevalences of schizophrenia, schizoaffective, and bipolar disorders were lower than that of depression.

A few studies compared schizophrenia with non-psychotic disorders. Spence and colleagues ${ }^{57}$ found that patients with schizophrenia $(n=40)$ showed a $75 \%$ prevalence of any childhood trauma compared to $23 \%$ in patients affected by non-psychotic depression or anxiety disorders $(n=30)$. The results were controlled for PTSD by excluding patients with this co-morbidity but the trauma definition included also serious injuries, accident, and natural disaster. Conversely, Friedman ${ }^{58}$ reported almost equal rates of physical and sexual abuse in four samples of patients with schizophrenia $(n=22)$, depression $(n=19)$, panic $(n=101)$ and other anxiety disorders including PTSD $(n=59)$. Between group comparison was limited by a non- homogenous gender distribution (more than $80 \%$ of female in panic and depression, but less than $50 \%$ in the other groups) that could have affected the results.

\section{THE ROLE OF SPECIFIC TYPE OF ADVERSITIES IN THE AETIOLOGY OF SCHIZOPHRENIA}

Is schizophrenia associated with a specific type of childhood abuse? According to a previous review, ${ }^{33}$ among ten studies that had investigated both sexual and physical abuse in psychotic disorders, 6 found a greater proportion of physical abuse, 4 reported more sexual abuse, and one observed the same prevalence of both. These results tend to be difficult to generalize as sexual and physical abuse have different frequency in the general population and the majority of the studies were uncontrolled. Other methodological challenges include the fact that, to some extent, different adversities tend to cluster in the same individuals and can be related to common risk factors (e.g. low socio-economic status ${ }^{59,60}$ ).

Three aforementioned surveys reported that the association of psychotic symptoms with childhood physical abuse was stronger than that with sexual molestation and rape, ${ }^{37,40,43}$ while another found no difference in the strength of the association. ${ }^{41}$ The AESOP study ${ }^{61}$ compared the prevalence of four types of abuse and neglect between a sample of first episode of psychosis ( $\mathrm{n}=182)$ and a matched population-based control group ( $\mathrm{n}=246)$; cases were nearly twice as likely to report physical but not sexual abuse, although, adjusting for demographic variables, the OR became non-significant. Intriguingly, the risk of psychosis was more strongly related to physical abuse perpetrated by the mother than by the father and, to some extent this applied also to maternal emotional abuse. ${ }^{62}$ Rubino and colleagues ${ }^{52}$ evaluated the prevalence of eight adverse childhood experiences in two groups of inpatients, one with schizophrenia $(n=174)$, and one with major depressive disorders $(n=305)$, and the general population $(n=310)$. While psychological abuse and emotional neglect were the most common experiences in the two clinical groups, increasing 5-17 times the likelihood of being a case, sexual abuse showed only a minor effect (OR 1.6-1.7). Physical abuse had the greatest impact on schizophrenia compared to depression, even when the estimate was adjusted for multiple abuse (OR 1.46).

\section{PUTATIVE MEDIATING AND MODERATING FACTORS: GENDER, AFFECTIVE AND POST-TRAUMATIC SYMPTOMS, AND SUBSTANCE MISUSE}

Among the general population childhood abuse affects more girls than boys, and in particular the former are more exposed to sexual molestation and rape. ${ }^{7,63}$ These findings have been largely but not completely replicated in people with severe mental disorders, within whom women are more exposed to multiple forms of maltreatment ${ }^{31,32}$ and more likely to report not only sexual but also physical abuse. ${ }^{61,64}$ While a single study ${ }^{37}$ suggested that, due to subversion of cultural expectation, rape had a stronger effect in men, others did not confirm this. $^{42,45}$

As mentioned, depression and post-traumatic disorders are the most common psychiatric outcome of childhood trauma. Epidemiological studies showed that when the relationship between early adversities and psychotic symptoms was controlled for depressive symptoms, the size of the effect was decreased though still significant. ${ }^{37,40,42}$ The mediating effect of post-traumatic symptoms has been less investigated though according to the literature these affect from $13 \%$ to $53 \%$ of patients with schizophrenia, ${ }^{65-67}$ particularly those exposed to child trauma (OR $1.53^{68}$ to $3.52^{69}$ ). It has been suggested that PTSD worsens the clinical outcome of severe mental disorders ${ }^{31,70}$ by enhancing hyper-arousal, ${ }^{65}$ dissociation, ${ }^{71-73}$ and reexperiencing symptoms, these latter expressed as trauma-based hallucinations. ${ }^{74,75}$

The relationship between childhood adverse experiences and later substance misuse has received growing attention in the last few years, providing evidence of increased drug use in 


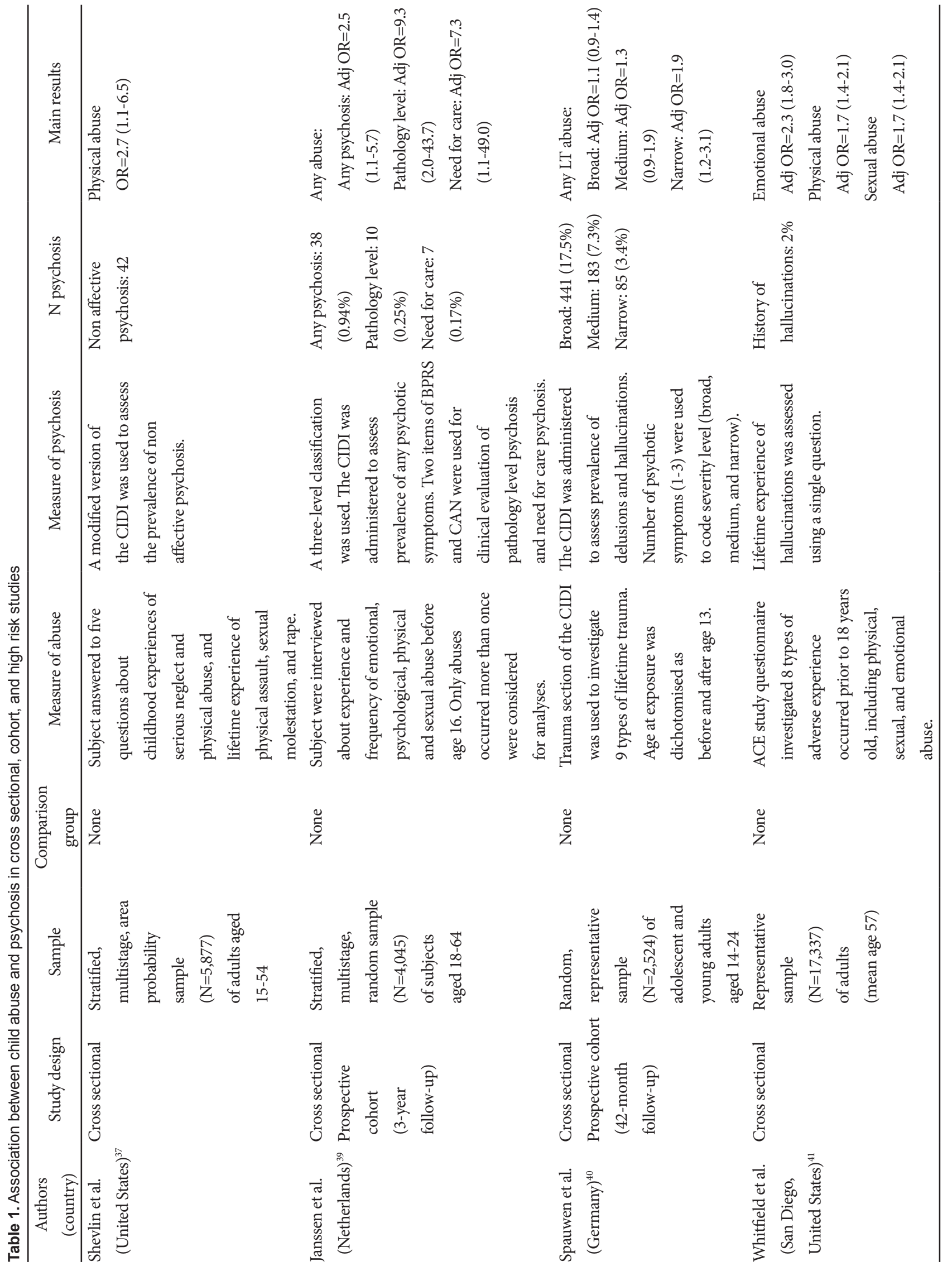




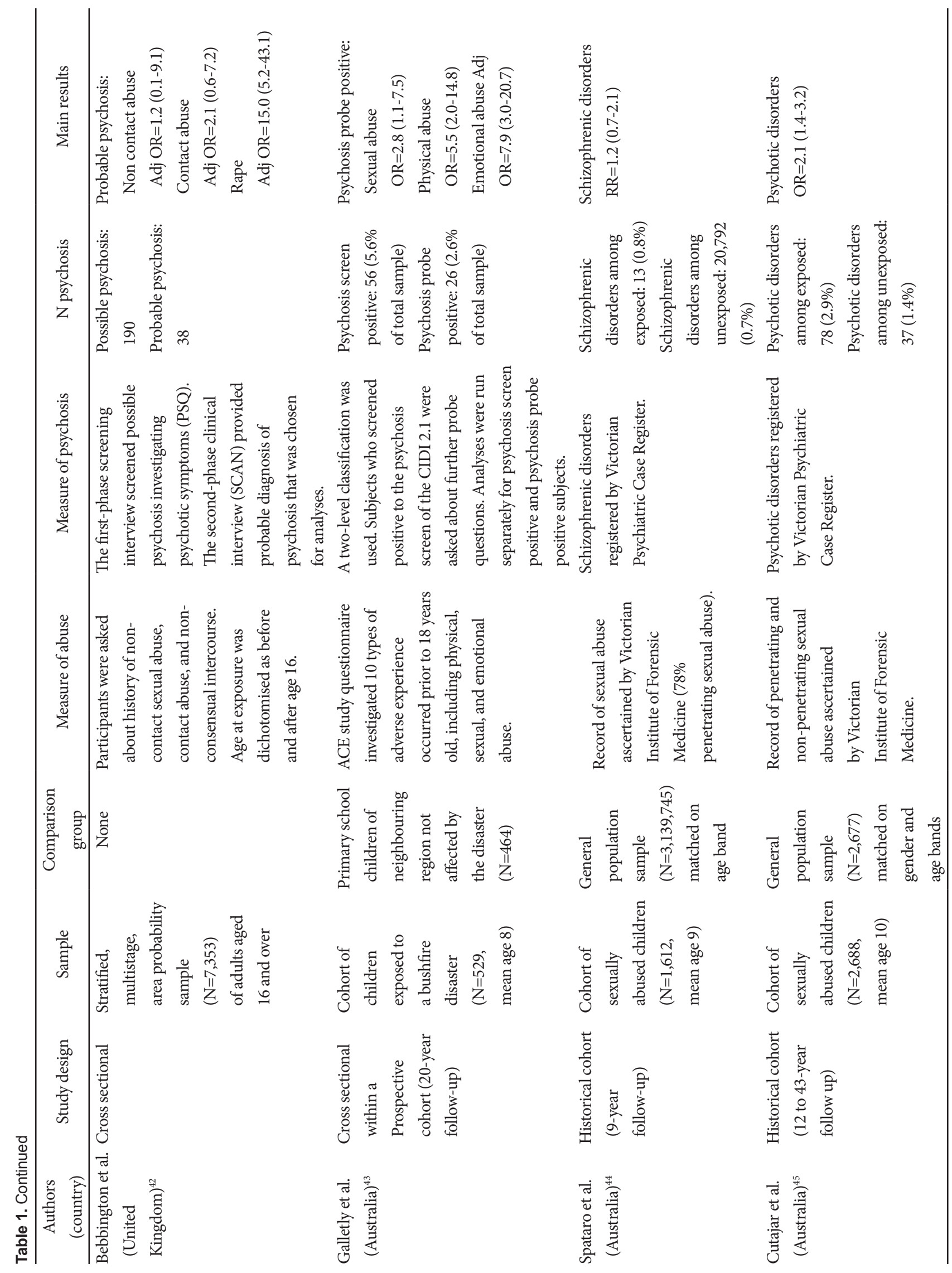




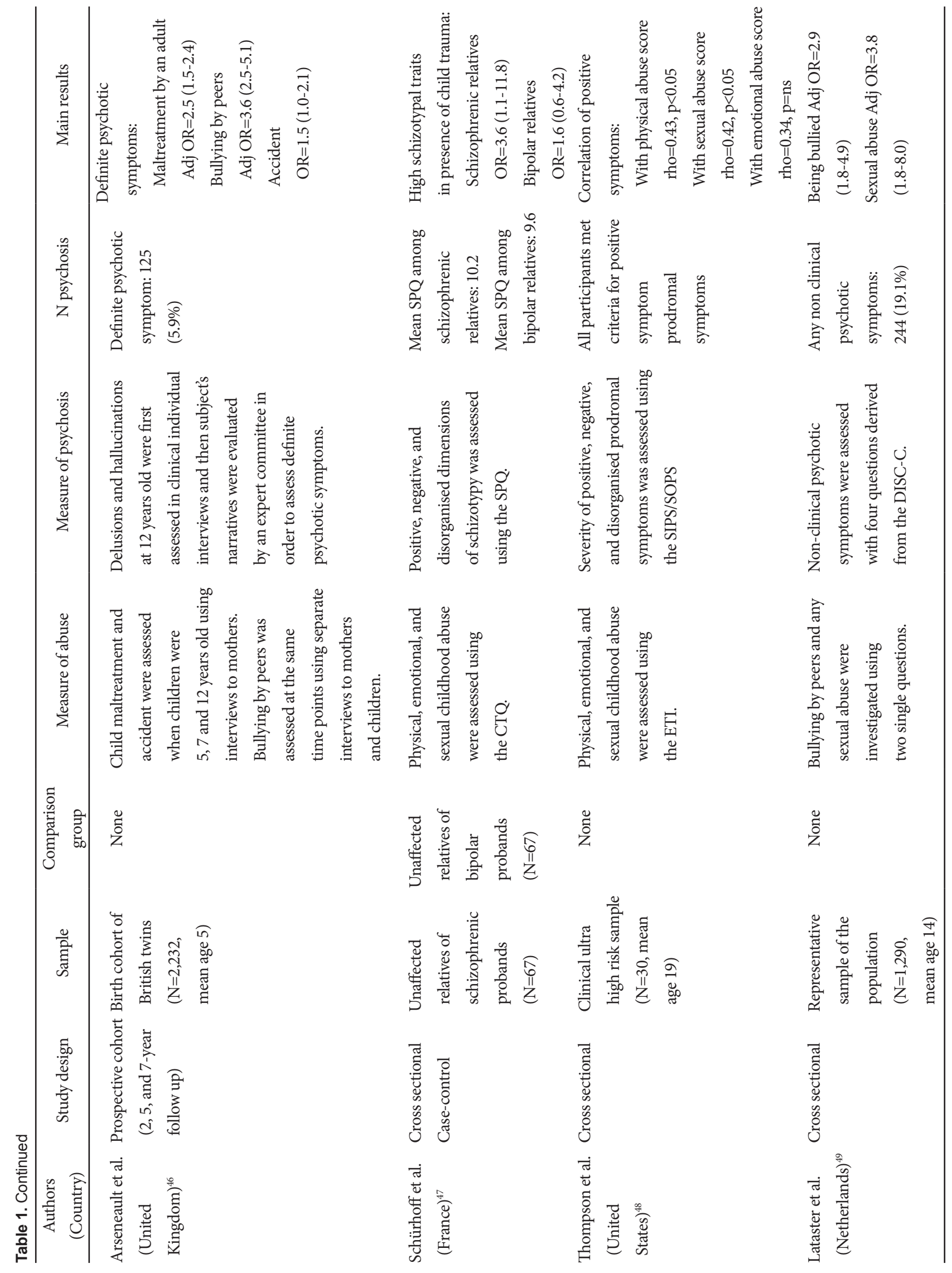




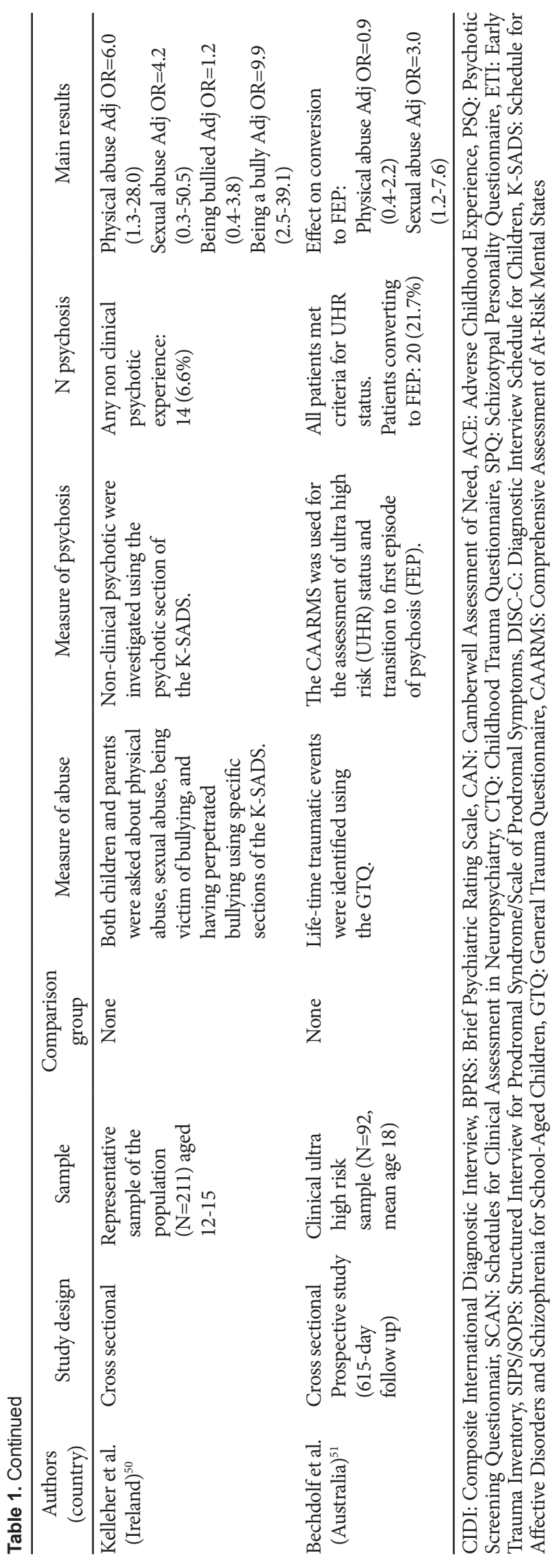

patients who were exposed to abuse in childhood. ${ }^{76,77}$ Five recent papers focused on the interaction between childhood trauma, cannabis use and psychosis. In two representative samples, it was found that the combined effect of the two exposures was stronger than either main effect, suggestive of an additive interaction. ${ }^{78,79}$ The APMS found the effect of cannabis use became non-significant after controlling for childhood abuse $^{80}$ and the NCS reported a multiplicative interaction, in the context of non-significant main effects, ${ }^{81}$ but no interaction was found in the EDSP. ${ }^{82}$ When the cumulative effect of environmental exposures (urbanicity, cannabis use, and child adversities) was estimated together with psychotic proneness, synergistic interaction accounted up to $83 \%$ of the risk for psychotic disorders. ${ }^{83}$

\section{MECHANISM OF RISK}

A growing body of literature has investigated pathogenic pathways that link early and recent psychosocial stress to psychotic disorders, identifying in sensitization a possible mechanism through which environmental risk factors could affect the onset of psychosis. ${ }^{84,85}$ Originally applied to psychosis to explain the psychotogenic effects of stimulant drugs ${ }^{86}$ sensitization postulates that a repetitive exposure to an environmental risk factor progressively increases the biological and behavioural response, leading to over-reactivity ${ }^{87,88}$ It is hypothesised that, in predisposed individuals, psychosocial stressors trigger psychotic symptoms by disrupting cognitive processes and/or implementing emotional changes that, in turn, increase the psychopathological risk related to later events..$^{89}$ Indeed, in the non clinical population, childhood trauma was found to enhance emotional reactivity to mild intensity stressors. ${ }^{90}$ Furthermore, people affected by psychosis show an over-reactivity to daily life stress (in terms of reduced positive and increased negative emotions) that is associated with psychotic symptom severity. ${ }^{91,92}$

A number of animal and human studies have reported that acute stress stimulates dopamine release in the striatum, and that patients with schizophrenia exhibit a greater dopaminergic reactivity compared to healthy controls; these findings are also supported by in vivo studies involving stressful psychosocial tasks such as public speaking or arithmetic. ${ }^{85,93}$ Consistent with the sensitization hypothesis, an experiment in healthy volunteers reported a significant interaction between low maternal care and enhanced dopamine release in response to psychosocial stress. ${ }^{94,95}$ It has been also documented that child abuse produces enduring changes in the Hypothalamus-Pituitary-Adrenal (HPA) axis by decreasing basal cortisol levels, reducing hippocampal volume, and increasing adenocorticotrophic (ACTH) reactivity in adults affected by various form of 
psychopathology ${ }^{96,97}$ It is obviously important to ascertain whether similar changes occur in psychosis but studies of this are scarce. ${ }^{98,99} \mathrm{~A}$ recent review highlights the fact that, although schizophrenic patients usually display increased cortisol, they tend to have a blunted cortisol response to mild psychological stressors such as awakening. ${ }^{100}$ Thus, a study comparing those with their first episode of psychosis and healthy controls, found that patients had higher cortisol level during the day but diminished cortisol response to awakening. ${ }^{99}$ While in controls diurnal cortisol levels positively correlated with recent life events and, at trend level, with extent of childhood abuse, such a relationship was not found in patients. In this latter group, stressful life events were negatively correlated with diurnal cortisol levels, and early sexual abuse was positively correlated with the cortisol awakening response. These differences might be explained by the fact that hyperactivation of the HPA axis leads to an impaired regulation of the HPA axis ${ }^{101,102}$ that, in turn, produces a blunted response to daily life stressors - which represents a specific feature of schizophrenia, not found in depression but similar to that observed in post-traumatic stress disorder. ${ }^{99}$

Although the relationship between the HPA axis and the dopamine system needs to be clarified, preliminary research reported a positive correlation between glucorticoid levels and dopaminergic activity and, conversely, increased cortisol secretion following pro-dopaminergic drugs that are suggestive of a reciprocal influence between the two systems. ${ }^{101}$ Furthermore, earlier research on genetic modulation of psychopathological risk related to stress and trauma supports the involvement of genes related to dopamine metabolism (particularly MAO-A and COMT) and glucocorticoid receptors sensitivity (FKBP5) together with brain derived neurotrophic factor (BDNF). ${ }^{85,97}$ The effect of BDNF and childhood adversities on psychotic symptoms has been explored by two studies. In a general population sample, Alemany and colleagues ${ }^{103}$ found that BDNF-Val66Met polymorphism moderated the risk for subclinical psychotic experience associated with childhood abuse. An association between lower BDNF expression and childhood trauma in a FEP sample was described by Mondelli et al. ${ }^{104}$ In this study, diurnal cortisol levels, interleukin 6, and BDNF independently predicted a smaller hippocampal volume in patients, suggesting that psychosocial stressors might affect brain structure through an effect on BDNF.

\section{CONCLUSION}

Childhood abuse is attracting increasing attention as a possible risk factor for psychotic disorders. Supporting evidence is mainly provided by population-based surveys, according to which, the odds of psychotic symptoms range from 1.7 to 15 in victims of abuse compared to the unexposed, ${ }^{37,39-42}$ the risks tend to be higher in those exposed to more severe experience of abuse (e.g. sexual molestation vs. rape) and to multiple childhood adversities, suggesting a dose response relationship. ${ }^{38-40}$ However, longitudinal studies are $\operatorname{rare}^{44-46}$ and, so far, have provided inconsistent data concerning a specific risk for psychotic disorders in victims of childhood trauma. Whereas cohort studies on depressive disorders assessed the confounding effects of genetic load, child temperament, and other family risk factors, ${ }^{8}$ such analyses have not been carried out regarding psychosis, with the notable exception of the study of Arseneault. ${ }^{46}$ Therefore, the possibility cannot be ruled out that a child destined to develop schizophrenia may show characteristics in childhood that increase the risk of abuse.

Specificity of childhood abuse in psychotic disorders and, particularly, in schizophrenia has not been demonstrated. Indeed, when psychotic disorder is compared with other psychiatric outcomes, epidemiological studies show only a weak effect, ${ }^{40,44,45}$ though case-control studies suggest a higher prevalence of childhood adversities among patients with schizophrenia and bipolar disorder than with major depression. ${ }^{52,53}$ The picture is further clouded by the prevalence of post-traumatic symptoms in patients affected by schizophrenia who were abused as child ${ }^{68,69}$ further research needs to address the possible mediating role of PTSD.

With regards to specificity of effect of different types of abuse, preliminary evidence suggests that intentional violence has a stronger effect than accidental trauma $\mathrm{a}^{40,43,46}$ and physical and psychological abuse have comparable or greater impact than other forms of maltreatment, ${ }^{37,52,62}$ especially if perpetrated by maternal figure. ${ }^{62}$ Furthermore, it appears that the general effect of childhood adversities, not only sexual abuse, tends to be stronger in females ${ }^{31,32,61}$ and in drug and cannabis users. ${ }^{76-79}$

However, the case cannot be regarded as proven. So far none of the studies reported indicate that childhood abuse is either sufficient or necessary to develop a psychotic disorder. Instead, there are suggestion that early adversities, especially when severe or multiple, interact with genetic liability to psychosis ${ }^{46,51,83}$ and later environmental risk factors ${ }^{79,80}$ in increasing risk for psychosis. Prospective research is needed to a) better evaluate the trauma-related risk for psychosis in context of genetic susceptibility, b) to exclude the effect of reverse causality and c) to describe the relative weight of each factor. Similarly, research analysing the interaction between environmental risk factors (including migration, urbanicity, substance misuse, and recent life events) is required.

\section{REFERENCES}

1. Morgan C, Hutchinson G. The Sociodevelopmental Origins of Psychosis. In: Morgan C, Bhugra D, Editors. Principles of Social Psychiatry, 
Second Edition. Chichester, UK: JohnWiley \& Sons Ltd, 2010, p.193-213.

2. Bebbington PE, Bhugra D, Brugha T, Singleton N, Farrell M, Jenkins $\mathrm{R}$, et al. Psychosis, victimisation and childhood disadvantage: evidence from the second British National Survey of Psychiatric Morbidity. Br J Psychiatry 2004;185:220-226.

3. Rutter M, Sroufe LA. Developmental psychopathology: concepts and challenges. Dev Psychopathol 2000;12:265-296.

4. van Os J, Kenis G, Rutten BP. The environment and schizophrenia. Nature 2010;468:203-212.

5. Chen LP, Murad MH, Paras ML, Colbenson KM, Sattler AL, Goranson EN, et al. Sexual abuse and lifetime diagnosis of psychiatric disorders: systematic review and meta-analysis. Mayo Clin Proc 2010;85:618629.

6. Leeb R, Paulozzi L, Melanson C, Simon T, Arias I. Child Maltreatment Surveillance: Uniform Definitions for Public Health and Recommended Data Elements, Version 1.0. Atlanta, GA: US Department of Health and Human Services, CDC; 2008.

7. Gilbert R, Widom CS, Browne K, Fergusson D, Webb E, Janson S. Burden and consequences of child maltreatment in high-income countries. Lancet 2009;373:68-81.

8. Weich S, Patterson J, Shaw R, Stewart-Brown S. Family relationships in childhood and common psychiatric disorders in later life: systematic review of prospective studies. British J Psychiatry 2009;194:392-398.

9. Jonas S, Bebbington P, McManus S, Meltzer H, Jenkins R, Kuipers E, et al. Sexual abuse and psychiatric disorder in England: results from the 2007 Adult Psychiatric Morbidity Survey. Psychol Med 2011;41:709719.

10. Green JG, McLaughlin KA, Berglund PA, Gruber MJ, Sampson NA, Zaslavsky AM, et al. Childhood adversities and adult psychiatric disorders in the national comorbidity survey replication I: associations with first onset of DSM-IV disorders. Arch Gen Psychiatry 2010;67:113-123.

11. Alloy LB, Abramson LY, Smith JM, Gibb BE, Neeren AM. Role of parenting and maltreatment histories in unipolar and bipolar mood disorders: mediation by cognitive vulnerability to depression. Clin Child Family Psychol Rev 2006;9:23-64.

12. Paolucci EO, Genuis ML, Violato C. A meta-analysis of the published research on the effects of child sexual abuse. J Psychol 2001;135:17-36.

13. Al-Modallal H, Peden A, Anderson D. Impact of physical abuse on adulthood depressive symptoms among women. Issues Ment Health Nurs 2008;29:299-314.

14. Rind B, Tromovitch P, Bauserman R. A meta-analytic examination of assumed properties of child sexual abuse using college samples. Psychol Bull 1998;124:22-53.

15. Kearney CA, Wechsler A, Kaur H, Lemos-Miller A. Posttraumatic stress disorder in maltreated youth: a review of contemporary research and thought. Clin Child Fam Psychol Rev 2010;13:46-76.

16. Ozer EJ, Best SR, Lipsey TL, Weiss DS. Predictors of posttraumatic stress disorder and symptoms in adults: a meta-analysis. Psychol Bull 2003;129:52-73.

17. Cash SJ, Bridge JA. Epidemiology of youth suicide and suicidal behavior. Curr Opin Pediatr 2009;21:613-619.

18. Evans E, Hawton K, Rodham K. Factors associated with suicidal phenomena in adolescents: a systematic review of population-based studies. Clin Psychol Rev 2004;24:957-979.

19. Brodsky BS, Stanley B. Developmental effects on suicidal behavior: the role of abuse in childhood. Clin Neurosci Res 2001;1:331-336.

20. Afifi TO, Enns MW, Cox BJ, Asmundson GJ, Stein MB, Sareen J. Population attributable fractions of psychiatric disorders and suicide ideation and attempts associated with adverse childhood experiences. Am J Public Health 2008;98:946-952.

21. Afifi TO, Boman J, Fleisher W, Sareen J. The relationship between child abuse, parental divorce, and lifetime mental disorders and suicidality in a nationally representative adult sample. Child Abuse Negl 2009;33: 139-147.

22. Brezo J, Paris J, Vitaro F, Hébert M, Tremblay RE, Turecki G. Predict- ing suicide attempts in young adults with histories of childhood abuse. Br J Psychiatry 2008;193:134-139.

23. Fergusson DM, Boden JM, Horwood LJ. Exposure to childhood sexual and physical abuse and adjustment in early adulthood. Child Abuse Negl 2008;32:607-619.

24. Simpson TL, Miller WR. Concomitance between childhood sexual and physical abuse and substance use problems: A review. Clin Psychol Rev 2002;22:27-77.

25. Enoch MA. The role of early life stress as a predictor for alcohol and drug dependence. Psychopharmacology (Berl) 2011;214:17-31.

26. Widom CS, Marmorstein NR, White HR. Childhood victimization and illicit drug use in middle adulthood. Psychol Addict Behav 2006;20:394403.

27. Lansford JE, Dodge KA, Pettit GS, Bates JE. Does physical abuse in early childhood predict substance use in adolescence and early adulthood? Child Maltreat 2010;15:190-194.

28. MacMillan HL, Fleming JE, Trocmé N, Boyle MH, Wong M, Racine YA, et al. Prevalence of child physical and sexual abuse in the community. Results from the Ontario Health Supplement. JAMA 1997;278: 131-135.

29. Widom CS, White HR, Czaja SJ, Marmorstein NR. Long-term effects of child abuse and neglect on alcohol use and excessive drinking in middle adulthood. J Stud Alcohol Drugs 2007;68:317-326.

30. Dube SR, Miller JW, Brown DW, Giles WH, Felitti VJ, Dong M, et al. Adverse childhood experiences and the association with ever using alcohol and initiating alcohol use during adolescence. J Adolesc Health 2006;38:444.

31. Read J, van Os J, Morrison AP, Ross CA. Childhood trauma, psychosis and schizophrenia: a literature review with theoretical and clinical implications. Acta Psychiatr Scand 2005;112:330-350.

32. Morgan C, Fisher H. Environment and schizophrenia: environmental factors in schizophrenia: childhood trauma--a critical review. Schizophr Bull 2007;33:3-10.

33. Bendall S, Jackson HJ, Hulbert CA, McGorry PD. Childhood trauma and psychotic disorders: a systematic, critical review of the evidence. Schizophr Bull 2008;34:568-579.

34. Murray RM, Sham P, Van Os J, Zanelli J, Cannon M, McDonald C. A developmental model for similarities and dissimilarities between schizophrenia and bipolar disorder. Schizophr Res 2004;71:405-416.

35. Goodman LA, Thompson KM, Weinfurt K, Corl S, Acker P, Mueser $\mathrm{KT}$, et al. Reliability of reports of violent victimization and posttraumatic stress disorder among men and women with serious mental illness. J Trauma Stress 1999;12:587-599.

36. Fisher HL, Craig TK, Fearon P, Morgan K, Dazzan P, Lappin J, et al. Reliability and comparability of psychosis patients' retrospective reports of childhood abuse. Schizophr Bull 2011;37:546-553.

37. Shevlin M, Dorahy MJ, Adamson G. Trauma and psychosis: an analysis of the National Comorbidity Survey. Am J Psychiatry 2007;164:166169.

38. Shevlin M, Houston JE, Dorahy MJ, Adamson G. Cumulative traumas and psychosis: an analysis of the national comorbidity survey and the British Psychiatric Morbidity Survey. Schizophr Bull 2008;34:193-199.

39. Janssen I, Krabbendam L, Bak M, Hanssen M, Vollebergh W, de Graaf $\mathrm{R}$, et al. Childhood abuse as a risk factor for psychotic experiences. Acta Psychiatr Scand 2004;109:38-45.

40. Spauwen J, Krabbendam L, Lieb R, Wittchen HU, van Os J. Impact of psychological trauma on the development of psychotic symptoms: relationship with psychosis proneness. Br J Psychiatry 2006;188:527533.

41. Whitfield CL, Dube SR, Felitti VJ, Anda RF. Adverse childhood experiences and hallucinations. Child Abuse Negl 2005;29:797-810.

42. Bebbington P, Jonas S, Kuipers E, King M, Cooper C, Brugha T, et al. Childhood sexual abuse and psychosis: data from a cross-sectional national psychiatric survey in England. Br J Psychiatry 2011;199:29-37.

43. Galletly C, Van Hooff M, McFarlane A. Psychotic symptoms in young 
adults exposed to childhood trauma--a 20 year follow-up study. Schizophr Res 2011;127:76-82.

44. Spataro J, Mullen PE, Burgess PM, Wells DL, Moss SA. Impact of child sexual abuse on mental health: prospective study in males and females. Br J Psychiatry 2004;184:416-421.

45. Cutajar MC, Mullen PE, Ogloff JR, Thomas SD, Wells DL, Spataro J. Psychopathology in a large cohort of sexually abused children followed up to 43 years. Child Abuse Negl 2010;34:813-822.

46. Arseneault L, Cannon M, Fisher HL, Polanczyk G, Moffitt TE, Caspi A. Childhood trauma and children's emerging psychotic symptoms: a genetically sensitive longitudinal cohort study. Am J Psychiatry 2011;168: 65-72.

47. Schürhoff F, Laguerre A, Fisher H, Etain B, Méary A, Soussy C, et al. Selfreported childhood trauma correlates with schizotypal measures in schizophrenia but not bipolar pedigrees. Psychol Med 2009;39:365-370.

48. Thompson JL, Kelly M, Kimhy D, Harkavy-Friedman JM, Khan S, Messinger JW, et al. Childhood trauma and prodromal symptoms among individuals at clinical high risk for psychosis. Schizophr Res 2009;108:176-181.

49. Lataster T, van Os J, Drukker M, Henquet C, Feron F, Gunther N, et al. Childhood victimisation and developmental expression of nonclinical delusional ideation and hallucinatory experiences: victimisation and non-clinical psychotic experiences. Soc Psychiatry Psychiatr Epidemiol 2006;41:423-428.

50. Kelleher I, Harley M, Lynch F, Arseneault L, Fitzpatrick C, Cannon M. Associations between childhood trauma, bullying and psychotic symptoms among a school-based adolescent sample. Br J Psychiatry 2008; 193:378-382.

51. Bechdolf A, Thompson A, Nelson B, Cotton S, Simmons MB, Amminger GP, et al. Experience of trauma and conversion to psychosis in an ultrahigh-risk (prodromal) group. Acta Psychiatr Scand 2010;121:377-384.

52. Rubino IA, Nanni RC, Pozzi DM, Siracusano A. Early adverse experiences in schizophrenia and unipolar depression. J Nerv Ment Dis 2009; 197:65-68.

53. Aas M, Dazzan P, Fisher HL, Morgan C, Morgan K, Reichenberg A, et al. Childhood trauma and cognitive function in first-episode affective and non-affective psychosis. Schizophr Res 2011;129:12-19.

54. Darves-Bornoz J, Lemperiere T, Degiovanni A, Gaillard P. Sexual victimization in women with schizophrenia and bipolar disorder. Soc Psychiatry Psychiatr Epidemiol 1995;30:78-84.

55. Álvarez MJ, Roura P, Osés A, Foguet Q, Solà J, Arrufat FX. Prevalence and clinical impact of childhood trauma in patients with severe mental disorders. J Ner Ment Dis 2011;199:156-161.

56. Wexler BE, Lyons L, Lyons H, Mazure CM. Physical and sexual abuse during childhood and development of psychiatric illnesses during adulthood. J Ner Ment Dis 1997;185:522-524.

57. Spence W, Mulholland C, Lynch G, McHugh S, Dempster M, Shannon C. Rates of childhood trauma in a sample of patients with schizophrenia as compared with a sample of patients with non-psychotic psychiatric diagnoses. J Trauma Dissociation 2006;7:7-22.

58. Friedman S, Smith L, Fogel D, Paradis C, Viswanathan R, Ackerman $\mathrm{R}$, et al. The incidence and influence of early traumatic life events in patients with panic disorder: a comparison with other psychiatric outpatients. J Anxiety Disord 2002;16:259-272.

59. Drake B, Pandey S. Understanding the relationship between neighborhood poverty and specific types of child maltreatment. Child Abuse Negl 1996;20:1003-1018.

60. Coulton CJ, Crampton DS, Irwin M, Spilsbury JC, Korbin JE. How neighborhoods influence child maltreatment: a review of the literature and alternative pathways. Child Abuse Negl 2007;31:1117-1142.

61. Fisher H, Morgan C, Dazzan P, Craig TK, Morgan K, Hutchinson G, et al. Gender differences in the association between childhood abuse and psychosis. Br J Psychiatry 2009;194:319-325.

62. Fisher HL, Jones PB, Fearon P, Craig TK, Dazzan P, Morgan K, et al. The varying impact of type, timing and frequency of exposure to childhood adversity on its association with adult psychotic disorder. Psychol Med 2010;40:1967-1978.

63. Grubaugh A, Zinzow H, Paul L, Egede LE, Frueh BC. Trauma exposure and posttraumatic stress disorder in adults with severe mental illness: a critical review. Clin Psychol Rev 2011;31:883-899.

64. Neria Y, Bromet EJ, Sievers S, Lavelle J, Fochtmann LJ. Trauma exposure and posttraumatic stress disorder in psychosis: findings from a firstadmission cohort. J Consult Clin Psychol 2002;70:246-251.

65. Resnick SG, Bond GR, Mueser KT. Trauma and posttraumatic stress disorder in people with schizophrenia. J Abnorm Psychol 2003;112:415423.

66. Kilcommons AM, Morrison A. Relationships between trauma and psychosis: an exploration of cognitive and dissociative factors. Acta Psychiatr Scand 2005;112:351-359.

67. Weber K, Rockstroh B, Borgelt J, Awiszus B, Popov T, Hoffmann K, et al. Stress load during childhood affects psychopathology in psychiatric patients. BMC Psychiatry 2008;8:63.

68. Rosenberg SD, Lu W, Mueser KT, Jankowski MK, Cournos F. Correlates of adverse childhood events among adults with schizophrenia spectrum disorders. Psychiatr Serv 2007;58:245-253.

69. Mueser KT, Salyers MP, Rosenberg SD, Goodman LA, Essock SM, Osher FC, et al. Interpersonal trauma and posttraumatic stress disorder in patients with severe mental illness: demographic, clinical, and health correlates. Schizophr Bull 2004;30:45-57.

70. Mueser KT, Rosenberg SD, Goodman LA, Trumbetta SL. Trauma, PTSD, and the course of severe mental illness: an interactive model. Schizophr Res 2002;53:123-143.

71. Offen L, Waller G, Thomas G. Is reported childhood sexual abuse associated with the psychopathological characteristics of patients who experience auditory hallucinations? Child Abuse Negl 2003;27:919-927.

72. Ross CA, Keyes B. Dissociation and schizophrenia. J Trauma Dissociation 2004;5:69-83

73. Holowka DW, King S, Saheb D, Pukall M, Brunet A. Childhood abuse and dissociative symptoms in adult schizophrenia. Schizophr Res 2003; 60:87-90.

74. Hardy A, Fowler D, Freeman D, Smith B, Steel C, Evans J, et al. Trauma and hallucinatory experience in psychosis. J Ner Ment Dis 2005;193:501507.

75. Read J, Argyle N. Hallucinations, delusions, and thought disorder among adult psychiatric inpatients with a history of child abuse. Psychiatr Serv 1999;50:1467-1472.

76. Gearon JS, Kaltman SI, Brown C, Bellack AS. Traumatic life events and PTSD among women with substance use disorders and schizophrenia. Psychiatr Serv 2003;54:523-528.

77. Compton MT, Furman AC, Kaslow NJ. Preliminary evidence of an association between childhood abuse and cannabis dependence among African American first-episode schizophrenia-spectrum disorder patients. Drug Alcohol Depend 2004;76:311-316.

78. Harley M, Kelleher I, Clarke M, Lynch F, Arseneault L, Connor D, et al. Cannabis use and childhood trauma interact additively to increase the risk of psychotic symptoms in adolescence. Psychol Med 2010;40: 1627-1634

79. Konings M, Stefanis N, Kuepper R, de Graaf R, ten Have M, van Os J, et al. Replication in two independent population-based samples that childhood maltreatment and cannabis use synergistically impact on psychosis risk. Psychol Med 2012;42:149-159.

80. Houston JE, Murphy J, Shevlin M, Adamson G. Cannabis use and psychosis: re-visiting the role of childhood trauma. Psychol Med 2011;41: 2339-2348.

81. Houston JE, Murphy J, Adamson G, Stringer M, Shevlin M. Childhood sexual abuse, early cannabis use, and psychosis: testing an interaction model based on the National Comorbidity Survey. Schizophr Bull 2008; 34:580-585.

82. Kuepper R, Henquet C, Lieb R, Wittchen HU, van Os J. Non-replication of interaction between cannabis use and trauma in predicting psy- 
chosis. Schizophr Res 2011;131:262-263.

83. Cougnard A, Marcelis M, Myin-Germeys I, De Graaf R, Vollebergh W, Krabbendam L, et al. Does normal developmental expression of psychosis combine with environmental risk to cause persistence of psychosis? A psychosis proneness-persistence model. Psychol Med 2007; 37:513-527.

84. Howes OD, McDonald C, Cannon M, Arseneault L, Boydell J, Murray RM. Pathways to schizophrenia: the impact of environmental factors. Int J Neuropsychopharmacol 2004;7(Suppl 1):S7-S13.

85. van Winkel R, Stefanis NC, Myin-Germeys I. Psychosocial stress and psychosis. A review of the neurobiological mechanisms and the evidence for gene-stress interaction. Schizophr Bull 2008;34:1095-1105.

86. Lieberman JA, Kinon BJ, Loebel AD. Dopaminergic mechanisms in idiopathic and drug-induced psychoses. Schizophr Bull 1990;16:97-110.

87. Read J, Perry BD, Moskowitz A, Connolly J. The contribution of early traumatic events to schizophrenia in some patients: a traumagenic neurodevelopmental model. Psychiatry 2001;64:319-345.

88. Collip D, Myin-Germeys I, Van Os J. Does the concept of "sensitization" provide a plausible mechanism for the putative link between the environment and schizophrenia? Schizophr Bull 2008;34:220-225.

89. Garety PA, Kuipers E, Fowler D, Freeman D, Bebbington PE. A cognitive model of the positive symptoms of psychosis. Psychol Med 2001; 31:189-195.

90. Glaser JP, van Os J, Portegijs PJ, Myin-Germeys I. Childhood trauma and emotional reactivity to daily life stress in adult frequent attenders of general practitioners. J Psychosom Res 2006;61:229-236.

91. Myin-Germeys I, van Os J. Stress-reactivity in psychosis: evidence for an affective pathway to psychosis. Clin Psychol Rev 2007;27:409-424.

92. Oorschot M, Kwapil T, Delespaul P, Myin-Germeys I. Momentary assessment research in psychosis. Psychol Assess 2009;21:498-505.

93. Egerton A, Mehta MA, Montgomery AJ, Lappin JM, Howes OD, Reeves SJ, et al. The dopaminergic basis of human behaviors: a review of molecular imaging studies. Neurosci Biobehav Rev 2009;33:11091132.

94. Pruessner JC, Champagne F, Meaney MJ, Dagher A. Dopamine release in response to a psychological stress in humans and its relationship to early life maternal care: a positron emission tomography study using [11C] raclopride. J Neurosci 2004;24:2825-2831.

95. Soliman A, O’Driscoll GA, Pruessner J, Holahan ALV, Boileau I, Gagnon $\mathrm{D}$, et al. Stress-induced dopamine release in humans at risk of psychosis: a [11C]raclopride PET Study. Neuropsychopharmacology 2007;33:20332041.

96. Tarullo AR, Gunnar MR. Child maltreatment and the developing HPA axis. Horm Behav 2006;50:632-639.

97. McCrory E, De Brito SA, Viding E. Research Review: the neurobiology and genetics of maltreatment and adversity. J Child Psychol Psychiatry 2010;51:1079-1095.

98. Aas M, Dazzan P, Mondelli V, Toulopoulou T, Reichenberg A, Di Forti $\mathrm{M}$, et al. Abnormal cortisol awakening response predicts worse cognitive function in patients with first-episode psychosis. Psychol Med 2011; 41:463-476.

99. Mondelli V, Dazzan P, Hepgul N, Di Forti M, Aas M, D’Albenzio A, et al. Abnormal cortisol levels during the day and cortisol awakening response in first-episode psychosis: the role of stress and of antipsychotic treatment. Schizophr Res 2010;116:234-242.

100. Bradley AJ, Dinan TG. A systematic review of hypothalamic-pituitaryadrenal axis function in schizophrenia: implications for mortality. J Psychopharmacol 2010;24:91-118.

101. Walker E, Mittal V, Tessner K. Stress and the hypothalamic pituitary adrenal axis in the developmental course of schizophrenia. Annu Rev Clin Psychol 2008;4:189-216.

102. Pariante CM. Pituitary volume in psychosis: the first review of the evidence. J Psychopharmacol 2008;22:76-81.

103. Alemany S, Arias B, Aguilera M, Villa H, Moya J, Ibáñez MI, et al. Childhood abuse, the BDNF-Val66Met polymorphism and adult psychoticlike experiences. Br J Psychiatry 2011;199:38-42.

104. Mondelli V, Cattaneo A, Belvederi Murri M, Di Forti M, Handley R, Hepgul N, et al. Stress and inflammation reduce brain-derived neurotrophic factor expression in first-episode psychosis: a pathway to smaller hippocampal volume. J Clin Psychiatry 2011;72:1677-1684. 